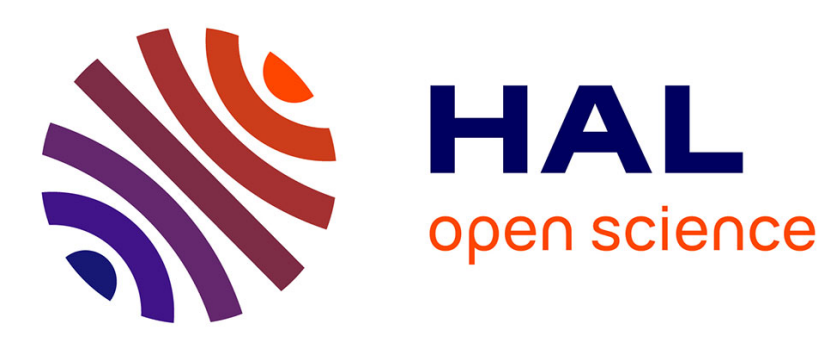

\title{
TRANSMISSION MEASUREMENTS UNDER GLANCING-INCIDENCE CONDITIONS
}

\author{
F. Rieutord
}

\section{To cite this version:}

F. Rieutord. TRANSMISSION MEASUREMENTS UNDER GLANCING-INCIDENCE CONDITIONS. Journal de Physique Colloques, 1989, 50 (C7), pp.C7-203-C7-206. 10.1051/jphyscol:1989721 . jpa-00229885

\section{HAL Id: jpa-00229885 https://hal.science/jpa-00229885}

Submitted on 1 Jan 1989

HAL is a multi-disciplinary open access archive for the deposit and dissemination of scientific research documents, whether they are published or not. The documents may come from teaching and research institutions in France or abroad, or from public or private research centers.
L'archive ouverte pluridisciplinaire HAL, est destinée au dépôt et à la diffusion de documents scientifiques de niveau recherche, publiés ou non, émanant des établissements d'enseignement et de recherche français ou étrangers, des laboratoires publics ou privés. 
COLLOQUE DE PHYSIQUE

Colloque C7, supplément au $\mathrm{n}^{\circ} 10$, Tome 50, octobre 1989

TRANSMISSION MEASUREMENTS UNDER GLANCING-INCIDENCE CONDITIONS

F. RIEUTORD

Institut Laue-Langevin, BP 156x, F-38042 Grenoble cedex, France

Résumé: Nous présentons une méthode permettant la mesure du coefficient de transmission d'une surface ou d'un film mince pour les rayons $X$ et les neutrons. La géométrie de l'expérience est décrite ainsi que les résultats obtenus sur un film multicouche déposé sur un substrat de silicium.

Abstract: We present a method allowing the measurement of the transmission coefficient of a surface or a thin film for X-rays and neutrons. The geometry of the experiment is described as well as results obtained on a multilayer film deposited on a silicon substrate .

\section{INTRODUCTION}

One of the main purposes of glancing-incidence techniques is to reduce bulk scattering with respect to surface scattering. Thus the transmitted beam is often considered in surface experiments as a nuisance responsible for bulk background scattering. The aim of this paper is to demonstrate that transmission measurements are feasible and that they provide valuable information complementing reflectivity data. We shall first present the method we developed to record the X-ray transmissivity as a function of incidence.

\section{GEOMETRY OF THE EXPERIMENT}

The basic idea of our experiments is to use Bragg diffraction on the reticular planes of a monocrystalline substrate to reflect the transmitted beam out of the bulk. Therefore we have to vary the incidence angle on the surface while maintaining the Bragg condition on a set of planes of the substrate. It can be seen on Fig.1 that this can be achieved by changing the angle $\varphi$ which amounts to a rotation of the normal to the substrate $\mathbf{n}_{\mathbf{s}}$ about the normal to the Bragg planes $\mathbf{n}_{\mathbf{B}}$.

The relation between the angle $\varphi$ and the angle of incidence $i$ is obtained from relations in the spherical triangle $\left(\mathbf{u}_{\mathbf{i}} \mathbf{n}_{\mathbf{s}} \mathbf{n}_{\mathbf{B}}\right)$

$$
\cos \varphi=\frac{\sin \theta_{B}-\sin i \cos \alpha}{\sin \alpha \cos i},
$$

where $\alpha$ is the angle between $\mathbf{n}_{\mathbf{S}}$ and $\mathbf{n}_{\mathbf{B}}$ and $\theta_{B}$ is the Bragg angle.

Practically, the incidence angle is set to the desired value, then the sample is rotated to the correct $\varphi$ and then the detector is moved to its correct position in order to record the diffracted beam. These measurements are best performed using a 4-circle diffractometer /1/. Equation (1) shows also that some Bragg reflections may not be suitable depending on the value of $\alpha$ and $\theta_{\mathrm{B}}$. The restriction of the method to monocrystalline substrates is not a real limitation since flat surfaces are often 
obtained with these samples. In principle, Bragg reflection from polycrystalline substrates may also be used, removing the condition of recording the diffracted beam out of the plane of incidence for surface reflection.

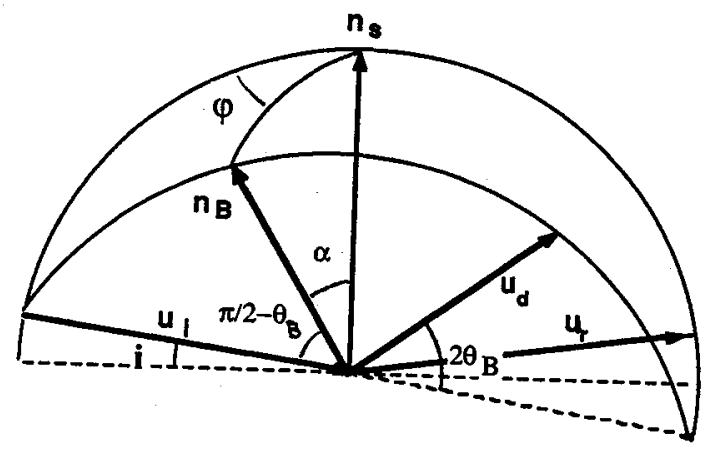

Fig. 1 - Geometry of the experiment. $\mathbf{n}_{\mathbf{s}}$ and $\mathbf{n}_{\mathrm{B}}$ are the normals to the surface and Bragg planes. $\mathrm{u}_{\mathrm{i}}, \mathrm{u}_{\mathrm{r}}, \mathrm{u}_{\mathrm{d}}$ are the directions of the incident, surface-reflected and diffracted beams, respectively.

The path of the beam in this geometry may be separated into three stages: namely a transmission through the surface or the thin film under the incidence $i$, a Bragg reflection on the reticular planesof substrate and then a second transmission from the substrate to the air under the (negative) incidence $o$. The intensity of the diffracted beam thus involves two transmissions and one reflection.

The fact that two transmissions occur at the same time is not a problem, for the output angle o (taken with respect to the surface) is related to the incidence angle $i$ through the relation

$$
\sin 0=-\sin i+2 \sin \theta_{B} \cos \alpha
$$

which shows that, recording diffraction from planes inclined with respect to the surface (i.e. $\alpha \neq 90^{\circ}$ ), $o$ and i cannot be small simultaneously. Since transmission tends to 1 for large angles, only one transmission will dominate.

The most general way of calculating the diffracted intensity is to use dynamical theory, our configuration corresponding to highly asymmetric Bragg-case diffraction $/ 2 /$. The presence of the thin stratified film is accounted for by a modification of the boundary conditions for the incident and diffracted wave-fields, replacing the simple continuity conditions for the electric and magnetic fields by matrix relations describing the propagation of the waves through the film. The full treatment of this problem with regard to our experimental geometry will be presented in detail in a forthcoming paper $/ 3 /$. Here, we shall give only a few results which will allow us to interpret most of the experimental results qualitatively.

\section{EXPERIMENTAL RESULTS}

The sample we have investigated is a 20 -layer $\mathrm{Ni} / \mathrm{C}$ film deposited by sputtering over a silicon [100] surface /4/. The low angle part of the experimental reflectivity is shown Fig.2. This curve exhibits the standard features of thin multilayered films. In particular, the first Bragg peak of the multilayer structure with secondary maxima is visible. Such a reflectivity diagram may be reproduced in detail from a model profile /5/. In our case, the mean index of the film is smaller than the indices of air and substrate.

Here, the [220] Bragg reflection was used to redirect the transmitted beam out of the bulk $\left(\alpha=45^{\circ}, \theta_{B}=23.65^{\circ}\right)$. The low incidence part of the diffraction curve is shown Fig. 3a. All the features expected for the transmission - i.e. features symmetrical to those of reflection - are visible as, for instance, a hollow peak with secondary maxima. The ratio of the height of the peak to the mean intensity level is the same as the absolute reflectivity in Fig.2. At incidence angles smaller than the critical angle for total reflection on the film $\theta_{\mathrm{cf}}$, the intensity is very small since the wave transmitted in the film is evanescent. Above $\theta_{\mathrm{cf}}$ the transmissivity, and thus the diffracted intensity, increase rapidly. This increase is however, slower than the drop in the reflection curve owing to the large 


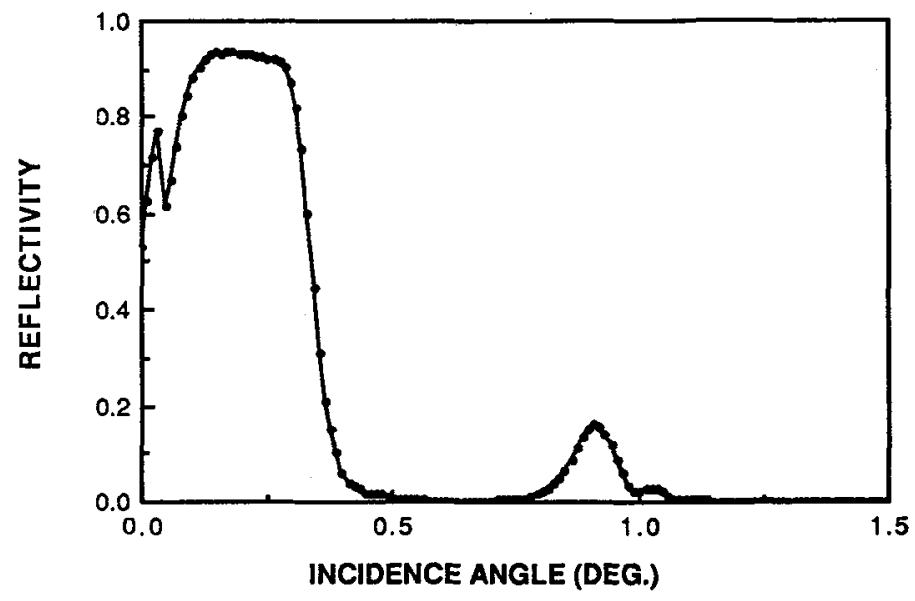

Fig. 2 - X-ray reflectivity of the silicon coated with the multilayer film ( $\left.\lambda_{\mathrm{CuK} \alpha}=1.54 \mathrm{~A}\right)$. Note the peak of the lamellar structure with secondary maxima. The critical angle $i_{\mathcal{C}}$ is $0.33^{\circ}$.
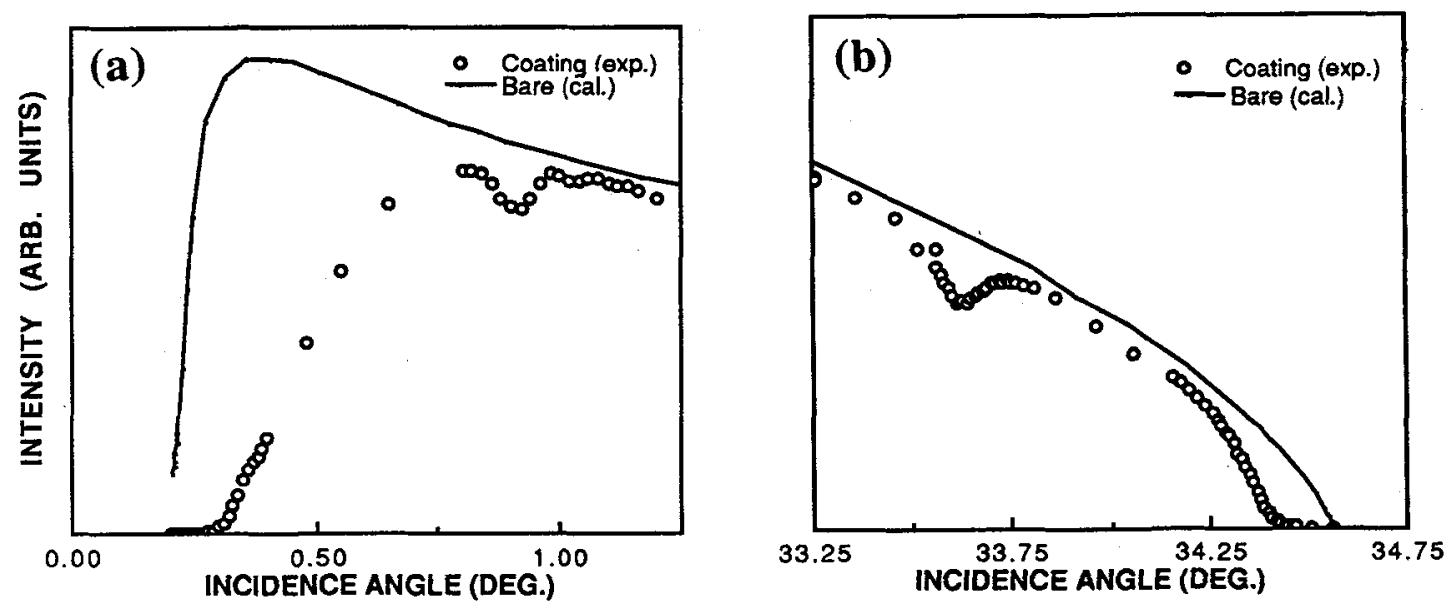

Fig. 3 - Intensity of the [220] silicon Bragg reflection as a function of the angle of incidence (with respect to the surface). (a) grazing input angle (b) grazing output angle. The solid line is the curve calculated for bare silicon. 
absorption in the film at grazing incidence. We have also plotted on Fig.3a the variation of the reflection coefficient calculated for the [220] Bragg planes of a bare silicon substrate. Since the critical angle $\theta_{\mathrm{cs}}$ for silicon is smaller than $\theta_{\mathrm{cf}}$ the corresponding drop in the reflection is invisible.

Transmission measurements can also be carried out with our method using glancing-incidence conditions for the outgoing beam. This corresponds to high-incidence angle in Eq(2). Fig.3b shows this large angle part of the diffraction curve. Here again we can recognize the main features of a transmission curve. However, the curve corresponds now to an inverted index profile starting in the substrate and ending in the air. For example the total reflection limit which appears as a break in the slope is now related to the difference between the indices of the film and the substrate. Since the index of silicon is smaller than that of the air $(1.0)$, no such feature appears on the bare silicon curve. Note that the calculated curve has been normalized to the experiment using the medium angle range.

\section{CONCLUSIONS}

We have demonstrated that transmission measurements are feasible. In principle, they may provide the same information as reflectivity i.e. an index profile. Of course the angular range is limited, since transmission requires the detection of a small variation within a large signal. Thus we rather believe that transmissivity should be considered as a complement of reflectivity measurements which may be especially useful in the following cases:

-When the surface covering film is absorbing, reflectivity is essentially sensitive to the topmost layers. Since it is possible to obtain "negative" incidences with the method, we can increase the sensitivity to the bottom layers.

-In the case of rough interfaces, the effect of roughnesses having the same amplitude but different lateral wavelengths may be very different on transmission and on reflection (especially if this lateral wavelength is close to the wavelength of the incident radiation).

-For neutrons, the reflection on supermirrors coatings is often used to select a polarization state. Our geometry may be a means to recover the other polarization state.

Acknowledgements

I wish to thank J.J.Benattar for his support and C.Blot for help during the experiments.

\section{REFERENCES}

/1/ The experimental part of this work has been carried out using a surface diffractometer of the X-ray group at the Service de Physique du Solide et de Resonance Magnetique in Saclay.

/2/ Bedynska, Phys.Stat.Sol.(a) 19 (1973) 365.

/3/ Rieutord to be published.

/4/ Lepetre Y., Rasigni G., Rivoira R., Philip R., Metois J.J., J. Opt. Soc. Am., A2 (1985) 1356.

15/ Rieutord F.,Benattar J.J., Rivoira R.,Lepetre Y., Blot C., Luzet D., Acta Cryst. A, in press. 